\title{
Effects of hydrolyzed yeast supplementation on growth performance, immunity, antioxidant capacity, and microbial shedding in weaning pigs
}

\author{
Waewaree Boontiam (D), Chalong Wachirapakorn (iD and Phreerapong Phaengphairee $\mathbb{D}$ \\ Department of Animal Science, Faculty of Agriculture, Khon Kaen University, Khon Kaen 40002, Thailand. \\ Corresponding author: Waewaree Boontiam, e-mail: waewbo@kku.ac.th \\ Co-authors: CW: chal_wch@kku.ac.th, PP: perpan@kku.ac.th \\ Received: 29-04-2020, Accepted: 03-08-2020, Published online: 18-09-2020
}

doi: www.doi.org/10.14202/vetworld.2020.1902-1909 How to cite this article: Boontiam W, Wachirapakorn C, Phaengphairee P (2020) Effects of hydrolyzed yeast supplementation on growth performance, immunity, antioxidant capacity, and microbial shedding in weaning pigs, Veterinary World, 13(9): 1902-1909.

\begin{abstract}
Background and Aim: Weaning pigs normally suffer from many stressors which have impaired growth performance and immunity. Hydrolyzed yeast has been proposed as an alternative feed additive. The aim of this study was to investigate the effects of various levels of hydrolyzed yeast (HY) supplementation in the feed of weaning pigs on growth performance, diarrhea incidence, immunity, antioxidant capacity, and microbial populations.

Materials and Methods: A total of 144 crossbred weaning pigs (Duroc $\times$ Landrace $\times$ Large White) with a mean body weight (BW) of $7.46 \mathrm{~kg}$ were randomly assigned to one of four treatments during a 5 -week feeding trial. Treatments consisted of a basal diet without HY inclusion (control), or the basal diet supplemented with HY at $0.5,1.0$, and $1.5 \mathrm{~g} / \mathrm{kg}$ of diet, respectively.

Results: Piglets fed with 1.0 or $1.5 \mathrm{~g} / \mathrm{kg}$ HY presented significantly increased $\mathrm{BW}(\mathrm{p}=0.009)$ and decreased incidence of diarrhea $(\mathrm{p}=0.001)$. The final BW $(\mathrm{p}=0.012)$, average daily gain $(\mathrm{p}=0.094)$, and average daily feed intake $(\mathrm{p}=0.091)$ showed a linear improvement with the level of HY inclusion. However, the gain-to-feed ratio was unaffected by dietary treatments. Linear responses to the HY supplementation levels were also observed for blood urea nitrogen $(\mathrm{p}=0.030)$, total protein $(\mathrm{p}=0.017)$, lymphocyte percentage $(\mathrm{p}=0.064)$, catalase activity $(\mathrm{p}=0.089)$, malondialdehyde (MDA) level $(\mathrm{p}=0.001)$, Salmonella spp. $(\mathrm{p}=0.024)$, Escherichia coli $(\mathrm{p}=0.021)$, and Lactobacillus spp. $(\mathrm{p}=0.048)$. Dietary inclusion of HY at 1.0 and $1.5 \mathrm{~g} / \mathrm{kg}$ resulted in increased immunoglobulin $\mathrm{A}$ and $\mathrm{G}$ secretions ( $\mathrm{p}=0.042$ and $\mathrm{p}=0.022$, respectively) and decreased MDA concentration $(\mathrm{p}<0.01)$ and Salmonella spp. $(\mathrm{p}=0.026)$ and E. coli $(\mathrm{p}=0.050)$.
\end{abstract}

Conclusion: It was concluded that HY inclusion at 1.0 and $1.5 \mathrm{~g} / \mathrm{kg}$ in the diet of weaning pigs improve BW, immunoglobulin secretion, and antioxidant enzyme activity, whereas it lowers diarrhea occurrence, lipid peroxidation, and pathogenic bacteria in weaning pigs.

Keywords: antioxidant capacity, growth performance, hydrolyzed yeast, immunity, weaning pigs.

\section{Introduction}

Post-weaning diarrhea (PWD) is of critical concern in swine production worldwide and can typically result in lower feed intake, growth retardation, and immune suppression [1]. A previous report has established that Escherichia coli is the predominant pathogenic strain causing PWD in piglets [2]. During colonization of the epithelial cells of the small intestine by the $E$. coli cells, it produces one or more enterotoxins that induce increased gut permeability, histological damage, and cytokine production [3], leading to increased morbidity and mortality in piglets. Numerous feed-based approaches have been used to investigate the modulatory effects of certain feed supplements on gut health and/or immunity in weaning pigs to improve disease resistance and growth performance $[4,5]$.

Copyright: Boontiam, et al. Open Access. This article is distributed under the terms of the Creative Commons Attribution 4.0 International License (http://creativecommons.org/licenses/ by/4.0/), which permits unrestricted use, distribution, and reproduction in any medium, provided you give appropriate credit to the original author(s) and the source, provide a link to the Creative Commons license, and indicate if changes were made. The Creative Commons Public Domain Dedication waiver (http:// creativecommons.org/publicdomain/zero/1.0/) applies to the data made available in this article, unless otherwise stated.
Hydrolyzed yeast (HY) is an end product of yeast extraction through hydrolysis, and it typically contains both yeast extract and yeast cell walls. Yeast cells are composed of mannan-oligosaccharides (MOS), and $\beta$-glucans, and their byproducts are known for their highly digestible protein, nucleotide, and amino acid (glutamic acid) contents [6]. The previous report showed that pigs fed with yeast-derived products exhibited recovery of intestinal integrity and immune responses after incidences of diarrhea [6]. The positive functions of yeast extract or yeast cells in modulating growth performance, immunity, balanced intestinal microbiota, and antioxidant capability of weaning pigs have also been documented [6-8]. Furthermore, improvements in intestinal mucosal structure and nutrient digestibility were reported for weaning pigs fed $1.2 \mathrm{~g} / \mathrm{kg}$ of a mixture of yeast cells and cell walls [6]. Similarly, growth performance and populations of beneficial bacteria improved with diets supplemented with $2 \mathrm{~g} / \mathrm{kg}$ of HY, in lactating sows [9]. Moreover, Tuoi et al. [10] reported that the percentage incidence of diarrhea and $E$. coli shedding decreased in piglets that were fed $1 \mathrm{~g} / \mathrm{kg}$ of yeast-derivative product.

The aim of this study was to investigate the effects of various levels of HY supplementation in the 
feed of weaning pigs on growth performance, incidence of diarrhea, immunity, antioxidant capacity, and microbial populations.

\section{Materials and Methods \\ Ethical approval}

All animal procedures used in this study were reviewed and approved by the Animal Care and Use Committee of Khon Kaen University (IACUC-KKU77/61).

\section{Study period and location}

This study was conducted from March to April 2019 at the University Farm of Khon Kaen University, Thailand.

\section{Animals, diet, and management}

A total of 144 piglets [Duroc $\times$ Landrace $\times$ Large White] weaned at 28 days of age with mean body weight (BW) of $7.46 \mathrm{~kg}$ were grouped in blocks by BW and gender and were randomly allotted one of four dietary treatments in a randomized complete block design. Each treatment consisted of six replicates, with six piglets (three gilts and three barrows) per pen. The weaning pigs were fed diets supplemented with various levels of HY for 5 weeks. The control basal diet did not include HY (Group 1), while the remaining groups were fed a basal diet with $\mathrm{HY}$ inclusion at 0.5 (Group 2, HY5), 1.0 (Group 3, HY10), and 1.5 (Group 4 , HY15) $\mathrm{g} / \mathrm{kg}$ of diet. The main active ingredients in HY were crude protein $(40 \%)$, free nucleotides $(3.5 \%), \beta$-glucans $(23 \%)$, MOS $(15 \%)$, and glutamic acid (4.9\%). The HY supplements were delivered as a top-dressing on the basal diet and prepared weekly to ensure feed freshness. The nutrient composition was calculated to meet or exceed National Research Council recommendation [11], as shown in Table-1. A mash diet was randomly chosen and kept in a sealed sample box for proximate analyses of crude protein, ether extract, and ash contents [12].

During the experiment, the piglets were maintained in pens $(0.96 \mathrm{~m} \times 2.16 \mathrm{~m}$, with a stocking density of $0.35 \mathrm{~m}^{2}$ per pig) with half-slatted concrete floors and in an open-housed environment. The temperature in the experimental house ranged from 20 to $23^{\circ} \mathrm{C}$ between $21: 00$ and $06: 00$ and from 28 to $32^{\circ} \mathrm{C}$ between 09:00 and 17:00, during the experimental period. Each pen contained a hemp sack, and a heating lamp at night during the 2 -week post-weaning period to ensure the required temperature for the piglets. The diets were administered to the pigs 3 times daily at 06:00, 12:00, and 17:00. All piglets had ad libitum access to the feed and drinking water through a selffeeder and nipple drinker, respectively, throughout the experimental period.

\section{Growth performance}

BW and feed intake were monitored on weeks 0,2 , and 5 post-weaning, and also used for evaluating average daily gain (ADG) and average daily feed intake (ADFI) evaluations. Per pen, the ADG and ADFI were
Table-1: Feed ingredients and nutrient composition of the basal diet (\% as fed basis).

\begin{tabular}{lc}
\hline Ingredient & \% as fed basis \\
\hline Broken rice & 52.16 \\
Full-fat soybean & 20.00 \\
Soybean meal (44\% CP) & 14.36 \\
Fish meal (58\% CP) & 5.00 \\
Skim milk & 5.00 \\
Dicalcium phosphate & 1.30 \\
Monocalcium phosphate & 1.15 \\
Sodium chloride & 0.33 \\
L-lysine monochloride (98\%) & 0.09 \\
DL-methionine & 0.31 \\
L-threonine & 0.05 \\
Vitamin-mineral premix ${ }^{1}$ & 0.25 \\
Total & 100.00 \\
Calculated composition & \\
Crude protein (\%) & 22.00 \\
Metabolizable energy, kcal/kg & 3,450 \\
Lysine (\%) & 1.41 \\
Methionine (\%) & 0.68 \\
Threonine (\%) & 0.92 \\
Tryptophan (\%) & 0.27 \\
Calcium (\%) & 1.01 \\
Total phosphorus (\%) & 1.04 \\
Analyzed composition & \\
Crude protein (\%) & 19.78 \\
Ether extract (\%) & 4.97 \\
Ash (\%) & 5.03 \\
\hline Supplied (per kilogram diet): Vitamin A as & \\
\hline
\end{tabular}

${ }^{1}$ Supplied (per kilogram diet): Vitamin $\mathrm{A}$ as retinol, 8,400 IU; Vitamin $\mathrm{D}_{3}, 945 \mathrm{IU}$; Vitamin E, $0.0126 \mathrm{~g}$; Vitamin $\mathrm{K}, 0.0021 \mathrm{~g}$; Vitamin $\mathrm{B}_{1}$ (thiamine), $0.0011 \mathrm{~g}$; Vitamin $\mathrm{B}_{2}$ (riboflavin), $0.0022 \mathrm{~g}$; Vitamin $\mathrm{B}_{6}$ (pyridoxine), $0.0016 \mathrm{~g}$; Vitamin $\mathrm{B}_{12}$ (cyanocobalamin), $0.02 \mathrm{mg}$; nicotinic acid, $0.0126 \mathrm{~g}$; pantothenic acid, $0.063 \mathrm{~g}$; folic acid, $0.0053 \mathrm{~g}$; biotin, $0.0315 \mathrm{mg}$; choline, $0.175 \mathrm{~g}$; copper as $\mathrm{CuSO}_{4}, 0.126 \mathrm{~g}$; iron as $\mathrm{FeSO}_{4}, 0.105 \mathrm{~g}$; manganese, $0.021 \mathrm{~g}$; cobalt, $0.0007 \mathrm{~g}$; iodine, $0.0007 \mathrm{~g}$; selenium as $\mathrm{Na}_{2} \mathrm{SeO}_{3}, 0.00007 \mathrm{~g}$

calculated by dividing the total weight gain and total feed intake, respectively, by the total number of experimental days. The gain-to-feed ratio (G:F) was calculated for each pig by dividing the ADG by the ADFI.

\section{Diarrheal score}

During post-weaning days 1-28, the number of diarrheic piglets per pen was monitored every morning at 06:00. Diarrheal occurrence was defined by the feces being soft and its moisture content over $75 \%$. Diarrheal rate (\%) was calculated by [total number of diarrheic piglets/(total number of piglets $\times$ days of experiment) $] \times 100$ [13].

\section{Blood collection and analysis}

Blood was collected on day 35 after overnight fasting using six healthy piglets (three barrows and three gilts, total $\mathrm{n}=24)$ per treatment. Blood $(5 \mathrm{~mL})$ was collected through an anterior vena cava puncture, using disposable syringes with needles. Blood samples $(3 \mathrm{~mL})$ were immediately transferred to a BD Vacutainer (Becton Dickinson Vacutainer System, Franklin Lakes, NJ, USA) with non-anticoagulant. All samples were kept at room temperature for $2 \mathrm{~h}$ and subsequently centrifuged for $10 \mathrm{~min}$ 
at $3000 \mathrm{~g}$ to separate the serum. The representative serum was used for further analyses of metabolic profiles, immunoglobulin concentrations, and antioxidant capacity.

Concentrations of aspartate aminotransferase (AST), blood urea nitrogen (BUN), and total protein were measured using commercial kits (Boehringer Mannheim, Germany), and their values were detected using an automatic blood analyzer. Antioxidant enzyme activity for catalase (CAT), glutathione peroxidase (GSH-Px), and malondialdehyde (MDA) was quantified using a spectrophotometer, following the manufacturer's instructions (Nanjing Jiancheng Bioengineering Institute, Nanjing, China). The immunoglobulin concentration was assayed with porcine immunoglobulin A (IgA) and immunoglobulin $\mathrm{G}(\mathrm{IgG})$ using Enzyme-linked immune-sorbent assay quantitation kits (Bethyl Laboratories, Inc., Montgomery, TX, USA). Each sample was analyzed in triplicate with 10 and 100 thousand-fold dilutions for the IgA and IgG assays, respectively. The absorbance of each sampling plate was detected within 30 min at $450 \mathrm{~nm}$ using an automatic microplate reader (Thermo Lab Systems, Finland). Values were presented as $\mathrm{mg} / \mathrm{mL}$. Aliquots $(2 \mathrm{~mL})$ of blood samples were transferred into heparinized tubes for assessing leukocyte percentages [14]. All blood-related criteria were analyzed in duplicate.

\section{Microbial shedding}

On day 35, approximately $2 \mathrm{~g}$ of fresh feces were directly sampled from the rectum of the piglets using manual stimulation of the internal and external sphincters. Fecal samples were diluted ten-fold in a sterile saline solution $(0.9 \%$, Becton, Dickinson and Co., Franklin Lakes, NJ, USA). Plates for Salmonella spp. (using Salmonella-Shigella agar) were incubated under anaerobic conditions at $37^{\circ} \mathrm{C}$ for $48 \mathrm{~h}$. The count of $E$. coli was enumerated in MacConkey agar for $24 \mathrm{~h}$ at $37^{\circ} \mathrm{C}$. Lactobacillus spp. was isolated on Rogosa and Sharpe agar with an overnight incubation (20-24 h) [15]. Typical colonies of each bacterium on each agar were immediately counted after removing from the incubator. The counts of microbial populations were log-transformed before statistical analysis was carried out. The results were presented as $\log _{10}$ colony-forming units/g.

\section{Statistical analysis}

All data were analyzed in a randomized complete block design using PROC GLM model in the SAS statistical software package (SAS University Edition). Each pen was an experimental unit for growth performance and diarrheal rate, whereas individually selected piglet was an experimental unit for blood metabolites and microbial counts. The recorded value of the $\log _{10}$ microbial count was transformed before analysis, and normality was verified with the Kolmogorov-Smirnov test. Significant differences among dietary treatments were evaluated by Duncan's new multiple range test at a probability value of $\mathrm{p} \leq 0.05$, whereas a tendency was assumed at a probability value between $p>0.05$ and $p<0.10$.

\section{Results}

\section{Growth performance and diarrheal occurrence}

The ADG, ADFI, and G:F ratio of the weaning pigs that were fed HY was unaffected by dietary treatment (Table-2). However, compared to the control, BW significantly improved in the HY-supplemented groups at 5 weeks $(p=0.009)$. Linear improvements in BW ( $p=0.012)$, ADG $(p=0.094)$, and ADFI $(p=0.091)$ were observed with increasing levels of HY inclusion. In addition, the piglets fed 1.0 and $1.5 \mathrm{~g} / \mathrm{kg}$ of $\mathrm{HY}$ had a significantly lower percentage of diarrheal incidence from 14 to 28 days than that in the control $(\mathrm{p}=0.002)$. Furthermore, the lower diarrheal rate was linearly influenced by increasing HY supplementation levels across all periods ( $\mathrm{p}=0.009, \mathrm{p}<0.001$, and $\mathrm{p}=0.014$, respectively).

\section{Blood profiles}

Dietary HY supplementation did not seem to affect the AST, BUN, and total protein concentrations (Table-3). However, a linear relationship was noted between increasing levels of HY and decreasing BUN concentrations $(\mathrm{p}=0.030)$ as well as increasing total protein concentration $(\mathrm{p}=0.017)$.

\section{Immunoglobulins and leukocytes}

The IgA and IgG concentrations increased significantly with HY supplementation at $1.5 \mathrm{~g} / \mathrm{kg}$ compared to that of the control diet $(\mathrm{p}=0.042, \mathrm{p}=0.022$, respectively) (Table-4). Increasing HY inclusion also enhanced IgA and IgG secretions, both of which showed linear responses $(p=0.009, p=0.003$, respectively). Furthermore, HY inclusion elicited a significant linear improvement in lymphocyte percentage $(p=0.064)$. However, the leukocyte percentages of neutrophils, monocytes, and eosinophils were unaffected across dietary treatments.

\section{Antioxidant enzyme and lipid peroxidation}

Lower MDA concentration was found in the HY-supplemented groups than that the control $(p<0.001)$. In addition, increasing levels of HY linearly and quadratically affected the concentrations of CAT $(\mathrm{p}=0.089, \mathrm{p}=0.074$, respectively) and $\mathrm{MDA}(\mathrm{p}<0.001$, $\mathrm{p}=0.022$, respectively) (Table-5). No significant difference was detected in GSH-Px concentration.

\section{Fecal microbial shedding}

Dietary HY supplementation reduced the population of Salmonella spp. $(\mathrm{p}=0.024, \mathrm{p}=0.016)$ and E. coli $(\mathrm{p}=0.021, \mathrm{p}=0.019)$ for the linear and quadratic responses, respectively, whereas the population of Lactobacillus spp. increased linearly with HY supplementation level ( $\mathrm{p}=0.048$; Table-6). The population of Salmonella spp. was lower with HY treatment than that with the control $(p=0.026)$. Furthermore, the 1.0 and $1.5 \mathrm{~g} / \mathrm{kg}$ HY inclusion levels significantly decreased $E$. coli shedding in the piglet feces compared to that of the control $(\mathrm{p}=0.050)$. 
Table-2: Effect of dietary hydrolyzed yeast supplementation on growth performance and diarrhea occurrence in weaning pigs ${ }^{1}$.

\begin{tabular}{|c|c|c|c|c|c|c|c|c|}
\hline \multirow[t]{2}{*}{ Criteria } & \multicolumn{4}{|c|}{ Hydrolyzed yeast supplementation } & \multirow[t]{2}{*}{ SEM } & \multicolumn{3}{|c|}{ Probability } \\
\hline & Control & HY5 & HY10 & HY15 & & Treatment & Linear & Quadratic \\
\hline \multicolumn{9}{|l|}{ BW (kg) } \\
\hline Initial & 7.33 & 7.57 & 7.53 & 7.42 & 0.440 & 0.979 & 0.880 & 0.966 \\
\hline $2^{\text {nd }}$ week & 10.26 & 11.34 & 11.64 & 11.80 & 0.582 & 0.273 & 0.116 & 0.134 \\
\hline $5^{\text {th }}$ week & $17.77^{\mathrm{B}}$ & $19.84^{\mathrm{A}}$ & $20.06^{A}$ & $19.77^{A}$ & 0.454 & 0.009 & 0.012 & 0.028 \\
\hline \multicolumn{9}{|l|}{ ADG $(g)$} \\
\hline $0-2$ week & 209.29 & 269.29 & 293.57 & 312.86 & 30.365 & 0.127 & 0.050 & 0.051 \\
\hline 3-5 week & 357.62 & 404.76 & 400.95 & 379.52 & 33.068 & 0.733 & 0.647 & 0.794 \\
\hline Overall & 298.29 & 350.57 & 358.00 & 352.86 & 19.621 & 0.152 & 0.094 & 0.134 \\
\hline \multicolumn{9}{|l|}{ ADFI (g) } \\
\hline 0-2 week & 356 & 377 & 386 & 396 & 22.551 & 0.645 & 0.286 & 0.301 \\
\hline 3-5 week & 690 & 789 & 778 & 768 & 30.436 & 0.130 & 0.091 & 0.287 \\
\hline Overall & 549 & 574 & 574 & 543 & 21.496 & 0.636 & 0.855 & 0.888 \\
\hline \multicolumn{9}{|l|}{ G/F ratio } \\
\hline 0-2 week & 0.59 & 0.71 & 0.76 & 0.79 & 0.102 & 0.641 & 0.347 & 0.272 \\
\hline 3-5 week & 0.52 & 0.51 & 0.52 & 0.50 & 0.047 & 0.970 & 0.728 & 0.933 \\
\hline Overall & 0.55 & 0.61 & 0.62 & 0.65 & 0.045 & 0.411 & 0.174 & 0.171 \\
\hline \multicolumn{9}{|c|}{ Diarrhea rate $(\%)$} \\
\hline 0-2 week & $5.04^{\mathrm{a}}$ & $4.26^{\mathrm{a}, \mathrm{b}}$ & $3.36^{\mathrm{b}}$ & $3.10^{\mathrm{b}}$ & 0.500 & 0.057 & 0.009 & 0.318 \\
\hline 3-4 week & $4.48^{\mathrm{A}}$ & $3.34^{\mathrm{A}, \mathrm{B}}$ & $2.94^{\mathrm{B}}$ & $2.66^{\mathrm{B}}$ & 0.282 & 0.002 & $<0.001$ & 0.024 \\
\hline Overall & $6.61^{a}$ & $5.19^{a, b}$ & $4.83^{b}$ & $4.43^{b}$ & 0.553 & 0.066 & 0.014 & 0.120 \\
\hline
\end{tabular}

HY5, HY10 and HY15 = Basal diet with hydrolyzed yeast supplementation at 0.51 .0 and $1.5 \mathrm{~g} / \mathrm{kg}$ diet, respectively. ${ }^{1}$ The pigs were fed the experimental diet from an average initial BW of $7.46 \mathrm{~kg}$ to a final BW of $19.36 \mathrm{~kg}$. $a, b \mathrm{Means}$ within the same row with different letters show a significant difference of $p<0.05$. A,BMeans within the same row with different letters show a significant difference of $\mathrm{p}<0.01$. BW=Body weight, $A D G=$ Average daily gain, ADFI=Average daily feed intake, SEM=Standard error of the mean

Table-3: Effect of dietary hydrolyzed yeast supplementation on blood profiles in weaning pigs ${ }^{1}$.

\begin{tabular}{|c|c|c|c|c|c|c|c|c|}
\hline \multirow[t]{2}{*}{ Criteria } & \multicolumn{4}{|c|}{ Hydrolyzed yeast supplementation } & \multirow[t]{2}{*}{ SEM } & \multicolumn{3}{|c|}{ Probability } \\
\hline & Control & HY5 & HY10 & HY15 & & Treatment & Linear & Quadratic \\
\hline AST (U/L) & 50.56 & 47.02 & 49.14 & 57.73 & 8.374 & 0.981 & 0882 & 0.955 \\
\hline BUN (mmol/L) & 6.56 & 4.02 & 3.53 & 3.89 & 0.795 & 0.061 & 0.030 & 0.190 \\
\hline Total protein $(\mathrm{g} / \mathrm{L})$ & 43.83 & 59.28 & 71.07 & 68.49 & 7.174 & 0.067 & 0.017 & 0.384 \\
\hline
\end{tabular}

HY5, HY10 and HY15=Basal diet with hydrolyzed yeast supplementation at 0.51 .0 and $1.5 \mathrm{~g} / \mathrm{kg}$ diet, respectively. ${ }^{1}$ Least squares means of six piglets per treatment. $\mathrm{AST}=$ Aspartate aminotransferase, BUN=Blood urea nitrogen, $\mathrm{SEM}=\mathrm{Standard}$ error of the mean

Table-4: Effect of dietary hydrolyzed yeast supplementation on secretory immunoglobulins and leukocyte counts in weaning pigs ${ }^{1}$.

\begin{tabular}{|c|c|c|c|c|c|c|c|c|}
\hline \multirow[t]{2}{*}{ Criteria } & \multicolumn{4}{|c|}{ Hydrolyzedyeast supplementation } & \multirow[t]{2}{*}{ SEM } & \multicolumn{3}{|c|}{ Probability } \\
\hline & Control & HY5 & HY10 & HY15 & & Treatment & Linear & Quadratic \\
\hline \multicolumn{9}{|l|}{ Immunoglobulin } \\
\hline $\operatorname{IgA}(\mathrm{mg} / \mathrm{mL})$ & $0.56^{\mathrm{b}}$ & $0.88^{\mathrm{a}, \mathrm{b}}$ & $0.95^{\mathrm{a}}$ & $1.03^{\mathrm{a}}$ & 0.111 & 0.042 & 0.009 & 0.102 \\
\hline $\operatorname{IgG}(\mathrm{mg} / \mathrm{mL})$ & $0.39^{\mathrm{B}}$ & $0.54^{A, B}$ & $0.66^{A, B}$ & $0.73^{\mathrm{A}}$ & 0.070 & 0.022 & 0.003 & 0.142 \\
\hline \multicolumn{9}{|c|}{ Leukocytes count (\%) } \\
\hline Lymphocytes & 49.17 & 61.83 & 67.50 & 71.67 & 8.166 & 0.272 & 0.064 & 0.319 \\
\hline Neutrophils & 39.33 & 33.02 & 29.57 & 30.66 & 4.009 & 0.348 & 0.121 & 0.525 \\
\hline Monocytes & 1.29 & 1.37 & 1.26 & 1.29 & 0.272 & 0.993 & 0.926 & 0.854 \\
\hline Eosinophils & 0.66 & 0.57 & 0.67 & 0.64 & 0.199 & 0.984 & 0.983 & 0.758 \\
\hline
\end{tabular}

HY5, HY10 and HY15=Basal diet with hydrolyzed yeast supplementation at 0.51 .0 and $1.5 \mathrm{~g} / \mathrm{kg}$ diet, respectively. ${ }^{1}$ Least squares means of six piglets per treatment. ${ }^{a, b}$ Means within the same row with different letters show a significant difference of $p<0.05$. A,B Means within the same row with different letters show a significant difference of $p<0.01$.

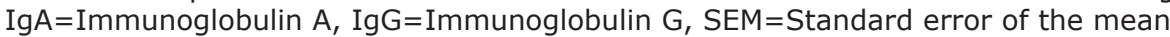

\section{Discussion}

Piglets fed HY grew faster than those that were fed the control diet. These findings are consistent with the results of $\mathrm{Hu}$ et al. [16], who observed significant increase in BW at 28 days in weaning pigs that were fed yeast-derived protein. Our study also found that increased HY levels induced ADFI in the piglets. The stimulation of feed intake found in this study was possibly influenced by the presence of glutamic acid and nucleotides in the yeast extract. The previous 
Available at www.veterinaryworld.org/Vol.13/September-2020/22.pdf

Table-5: Effect of dietary hydrolyzed yeast supplementation on serum antioxidant status in weaning pigs ${ }^{1}$.

\begin{tabular}{|c|c|c|c|c|c|c|c|c|}
\hline \multirow[t]{2}{*}{ Criteria } & \multicolumn{4}{|c|}{ Hydrolyzed yeast supplementation } & \multirow[t]{2}{*}{ SEM } & \multicolumn{3}{|c|}{ Probability } \\
\hline & Control & HY5 & HY10 & HY15 & & Treatment & Linear & Quadratic \\
\hline CAT $(\mathrm{U} / \mathrm{mL})$ & 2.54 & 4.42 & 3.94 & 4.23 & 0.565 & 0.121 & 0.089 & 0.074 \\
\hline GSH-Px $(\mathrm{U} / \mathrm{mL})$ & 303.57 & 370.69 & 394.33 & 384.32 & 51.483 & 0.606 & 0.266 & 0.587 \\
\hline $\operatorname{MDA}(\mathrm{nm} / \mathrm{mL})$ & $7.29^{A}$ & $4.76^{\mathrm{B}}$ & $3.41^{\mathrm{B}}$ & $2.97^{\mathrm{B}}$ & 0.578 & $<0.001$ & $<0.001$ & 0.022 \\
\hline
\end{tabular}

HY5, HY10 and HY15=Basal diet with hydrolyzed yeast supplementation at 0.51 .0 and $1.5 \mathrm{~g} / \mathrm{kg}$ diet, respectively. $A, B$ Means within the same row with different letters show a significant difference of $p<0.01$. CAT=Catalase, GSH$\mathrm{Px}=\mathrm{Glutathione} \mathrm{peroxidase,} \mathrm{MDA}=$ Malondialdehyde. ${ }^{1}$ Least squares means of six piglets per treatment, $\mathrm{SEM}=\mathrm{Standard}$ error of the mean

Table-6: Effect of dietary hydrolyzed yeast supplementation on fecal microbial shedding in weaning pigs ${ }^{1}$.

\begin{tabular}{|c|c|c|c|c|c|c|c|c|}
\hline \multirow[t]{2}{*}{ Criteria } & \multicolumn{4}{|c|}{ Hydrolyzed yeast supplementation } & \multirow[t]{2}{*}{ SEM } & \multicolumn{3}{|c|}{ Probability } \\
\hline & Control & HY5 & HY10 & HY15 & & Treatment & Linear & Quadratic \\
\hline \multicolumn{9}{|c|}{ Microbial shedding, $\log _{10} \mathrm{cfu} / \mathrm{g}$} \\
\hline Salmonella spp. & $6.67^{a}$ & $4.23^{b}$ & $4.94^{b}$ & $4.36^{b}$ & 0.553 & 0.026 & 0.024 & 0.016 \\
\hline Escherichia coli & $5.94^{a}$ & $4.18^{b}$ & $4.75^{a, b}$ & $3.65^{b}$ & 0.546 & 0.050 & 0.021 & 0.019 \\
\hline Lactobacillus spp. & 6.22 & 8.28 & 9.09 & 9.32 & 1.049 & 0.189 & 0.048 & 0.293 \\
\hline
\end{tabular}

HY5, HY10 and HY15=Basal diet with hydrolyzed yeast supplementation at $0.5,1.0$ and $1.5 \mathrm{~g} / \mathrm{kg}$ diet, respectively. ${ }^{1}$ Least squares means of six piglets per treatment. ${ }^{a, b}$ Means within the same row with different letters show a significant difference of $\mathrm{p}<0.05$. SEM $=$ Standard error of the mean

studies have used glutamic acid and nucleotides as flavor enhancers $[17,18]$, since they play an important role in stimulating the exocrine secretion of saliva and gastric and pancreatic juices, as well as binding to taste cell receptors in the oral cavity. This mechanism allows taste nerves in the umami taste region to be activated [17]. However, no improvement was observed in the G:F ratio with HY supplementation, as was also observed by Santos et al. [19]. Our data indicated that $\mathrm{HY}$ inclusion at up to $1.5 \mathrm{~g} / \mathrm{kg}$ of diet increased the $\mathrm{BW}$ of the piglets without affecting growth performance.

PWD results from an infection in the small intestine that inhibits the digestion and absorption capacity, with a consequent increase in the number of pathogenic bacteria in the large intestine [20]. In our study, the incidence of PWD decreased throughout the experimental period with the HY treatment, which corroborates the finding of Tuoi et al. [10], who observed lower incidence of diarrhea in piglets receiving a diet supplemented with a $1 \mathrm{~g} / \mathrm{kg}$ mixture of $\beta$-glucan and MOS. The lower occurrence of diarrhea in HY-fed animals may have been due to the reduced proliferation of enterotoxigenic bacteria in the gastrointestinal tract, thus resulting in greater suppression of pathogenic bacteria by the modulation of beneficial microbiota [21]. Although, HY can be used as a partial protein source for animals, high crude protein inclusion in diet has been reported to increase the rates of diarrhea in piglets due to high amounts of undigested proteins passing through the large intestine [22]. Pathogenic bacteria can use these substances for cell proliferation that subsequently leads to PWD in the piglets [22]. This is consistent with the quadratic response to the HY supplementation level from 3 to 4 weeks, although there was no effect observed for the overall period. One explanation for this result may be that the lower BUN concentration could perhaps increase protein utilization in piglets that were fed HY.

In our study, the positive effects of HY included a reduction in the abundance of pathogenic bacteria and lower incidence of diarrhea. Together, these results imply that HY supplementation restores healthy functioning of the gastrointestinal tract of piglets, during the post-weaning period.

\section{Metabolic profiles}

Blood metabolites can indicate the metabolic status of animals. Our results indicated an improvement in the total protein concentration in weaned pigs that were fed diets supplemented with HY, which is consistent with a previous study that used a yeast product as a partial alternative protein source for high protein availability in circulating blood [22]. Furthermore, dietary HY supplementation led to a significant decrease in the BUN concentration, indicating a high utilization of the yeast protein source by the weaned piglets, with less excretion of nitrogenous compound [23]. In this study, the increased rate of protein utilization led to a reduction in the level of undigested nitrogen, resulting in reduced proliferation of pathogenic bacteria in the feces of the weaned pigs. However, the AST concentration was unchanged by the HY-supplemented diets, indicating that the increased HY level did not result in damaged hepatocytes.

\section{Immunoglobulins and leukocytes}

Serum immunoglobulin levels can be used as an indicator of the humoral immune response in animals. Changes in the levels of these proteins can affect animal productivity and immunity. Both IgA and IgG are important for defense against pathogenic invasion [24,25]; IgA is abundant in breast milk and 
modulates piglet immunity through the gastric and intestinal mucosa [24], while $\operatorname{IgG}$ is abundant in the bloodstream [25]. This study found that piglets receiving HY-supplemented diets exhibited a greater production of IgA and IgG than those that fed on the control diet. Our results agree with those of the previous study [26], where it was shown that the contents of $\beta$-glucans, MOS, nucleotides, or small peptides in a HY-supplemented group contributed to activating immunoglobulin secretion. Wang et al. [26] showed that the inclusion of small peptides at $3 \mathrm{~g} / \mathrm{kg}$ increased increased immunoglobulin secretions in piglets. Furthermore, the presence of $\beta$-glucan in yeast cell walls has been shown to stimulate cytokine production and intestinal lymphocytes through modulation of Peyer's patches as a result of the activation of mucosal immunity [27]. Xiong et al. [6] have also reported a reduction in the number of neutrophil granulocytes with $\beta$-glucan-enriched diets. Although this positive effect has been confirmed in a previous study [28], it is in contrast with our finding. The different results obtained among the studies might have been influenced by the dosage of $\beta$-glucan, diet composition, or the status of individual piglets. In this study, stimulation of the immune system was detected as an increase in IgA and IgG concentrations, which would be important in defending against pathogenic bacteria through secondary immune response.

\section{Antioxidant enzyme and lipid peroxidation}

CAT and GSH-Px are important antioxidant enzymes in preventing cellular damage and maintaining cellular structure. Reduced concentrations of these enzymes lead to increased MDA secretion that can result in DNA damage [29,30]. Our study demonstrated that weaning pigs that were fed with HY could defend against free radicals through increased CAT activity. In agreement with this, Salobir et al. [31] showed that yeast-derived nucleotides can alleviate oxidative stress in piglets. In addition, the HY used in this study had a relatively greater quantity of glutamine that was included as an active precursor for glutathione biosynthesis. Published research has established the important function of glutathione in alleviating the effects of reactive oxygen species [30]. However, we did not observe an increase in GSH-Px activity with HY supplementation, which may have been due to a higher CAT level than that of GSH-Px, normally found in hepatocytes. In addition, CAT may have initially converted hydrogen peroxide to water and oxygen before being eliminated by the activity of GSH-Px, resulting in reduced MDA production, as has been previously observed [32].

\section{Fecal microbial shedding}

The gut microbiota are important for the maintenance of gut homeostasis in animals [33]. We observed that potential components of the yeast cell wall or yeast extract present in HY, stimulate beneficial bacteria, immune responses, and protect against pathogens in the digesta. In our study, the populations of Salmonella spp. and E. coli decreased, while that of Lactobacillus spp. increased with HY supplementation. This finding is in agreement with that of Tuoi et al. [10], who observed that inclusion of combinations of $1.0 \mathrm{~g} / \mathrm{kg} \beta$-glucan and MOS in the piglet diet markedly increased the abundance of Lactobacillus spp. However, this contrasted with a previous report in which an increase in intestinal microbiota was not observed [34]. These inconsistent results may be due to the different inclusion levels, dietary compositions, or HY purity utilized. $\beta$-Glucan and MOS are reported to be active non-starch polysaccharides that likely promote the expansion of Lactobacillus and Bifidobacteria populations [10,16] and reduce those of E. coli and Salmonella spp. in weaning pigs [35]. The regulation of gut microbiota found in our study was supported by the increased lymphocyte percentages and concentrations of secreted $\operatorname{IgA}$ and $\operatorname{IgG}$. This approach could be applied in feed formulations for piglets to balance their gut microbiota during the weaning period.

\section{Conclusion}

Piglets fed with HY at 1.0 and $1.5 \mathrm{~g} / \mathrm{kg}$ of diet showed significantly improved BW and immunoglobulin secretion, as well as decreased diarrheal occurrence, MDA concentration, and populations of E. coli and Salmonella spp.

\section{Authors' Contributions}

WB designed and performed the experiment, collected the data, interpreted data, wrote and revised the manuscript. CW supervised the study. PP performed the statistical analysis. All authors read and approved the final manuscript.

\section{Acknowledgments}

The authors would like to thank the Department of Animal Science at Khon Kaen University, Thailand, for supporting experimental diets and the research facility. The authors also acknowledge the partial financial grant under the Young Researcher Development Project of Khon Kaen University, Thailand.

\section{Competing Interests}

The authors declare that they have no competing interests.

\section{Publisher's Note}

Veterinary World remains neutral with regard to jurisdictional claims in published institutional affiliation.

\section{References}

1. Rhouma, M., Fairbrother, J.M., Beaudry, F. and Letellier, A. (2017) Post weaning diarrhea in pigs: Risk factors and 
non-colistin-based control strategies. Acta. Vet. Scand., 59(31): 1-19.

2. Nagy, B., Whipp, S.C., Imberechts, H., Bertschinger, H.U., Dean-Nystrom, E.A., Casey, T.A. and Salajka, E. (1997) Biological relationship between F18ab and F18ac fimbriae of enterotoxigenic and verotoxigenic Escherichia coli from weaned pigs with oedema disease or diarrhoea. Microb. Pathog., 22(1): 1-11.

3. Tarr, P.I., Carrie, C.A. and Chandler, W.L. (2015) Shigatoxin-producing Escherichia coli and haemolytic uraemic syndrome. Lancet, 365(3): 1073-1086.

4. $\quad$ Long, S.F., Xu, Y.T., Pan, L., Wang, Q.Q., Wang, C.L., Wu, J.Y., Wu, Y.Y., Han, Y.M., Yun, C.H. and Piao, X.S. (2018) Mixed organic acids as antibiotic substitutes improve performance, serum immunity, intestinal morphology and microbiota for weaned piglets. Anim. Feed Sci. Technol., 235(6): 23-35

5. Kim, K., Ehrlich, A., Perng, V., Chase, J.A., Raybould, H., Li, X., Atwill, E.R., Whelan, R., Sokale, A. and Liu, Y. (2019) Algae-derived $\beta$-glucan enhanced gut health and immune responses of weaned pigs experimentally infected with a pathogenic E. coli. Anim. Feed Sci. Technol., 248(8): 114-125.

6. Xiong, X., Yang, H., Li, B., Liu, G., Huang, R., Li, F., Liao, P., Zhang, Y., Nyachoti, C.M. and Deng, D. (2015) Dietary supplementation with yeast product improves intestinal function, and serum and ileal amino acid contents in weaned piglets. Livest. Sci., 171(1): 20-27.

7. Sauer, N., Eklund, M., Roth, S., Rink, F., Jezierny, D., Bauer, E. and Mosenthin, R. (2012) Short-term effect of dietary yeast nucleotide supplementation on small intestinal enzyme activities, bacterial populations, and metabolites and ileal nutrient digestibilities in newly weaned pigs. $J$. Anim. Physiol. Anim. Nutr., 96(4): 700-708.

8. Liu, G., Lei, Y., Martínez, Y., Ren, W., Ni, H., Al-Dhabi, N.A., Duraipandiyan, V. and Yin, Y. (2017) Dietary Saccharomyces cerevisiae cell wall extract supplementation alleviates oxidative stress and modulates serum amino acids profiles in weaned piglets. Oxid. Med. Cell. Longev., 2017(5): Article ID 3967493.

9. Hasan, S., Junnikkala, S., Peltoniemi, O., Paulin, L., Lyyski, A., Vuorenmaa, J. and Oliviero, C. (2018) Dietary supplementation with yeast hydrolysate in pregnancy influences colostrum yield and gut microbiota of sows and piglets after birth. PLoS One, 13(5): Article ID 0197586.

10. Tuoi, P.T., Assavacheep, P., Angkanaporn, K. and Assavacheep, A. (2016) Effects of $\beta$-glucan and mannan-oligosaccharide supplementation on growth performance, fecal bacterial population, and immune responses of weaned pigs. Thai. J. Vet. Med., 46(4): 589-599.

11. National Research Council. (1998) Nutrient Requirements of Swine. National Academy Press, Washington, DC, USA.

12. AOAC. (1995) Official Methods of Analysis. $16^{\text {th }}$ ed. AOAC, Washington, DC, USA.

13. Hu, C.H., Song, J., Li, Y.L., Luan, Z.S. and Zhu, K. (2013) Diosmectite-zinc oxide composite improves intestinal barrier function, modulates expression of pro-inflammatory cytokines and tight junction protein in early weaned pigs. Br. J. Nutr., 110(4): 681-688.

14. Sipos, W., Duviqneau, C.J. and Schwendenwein, I. (2011) Exploratory reference intervals on hematology and cellular immune system of multiparous large white sows. Vet. Immunol. Immunopathol., 141(3): 307-311.

15. Xie, Y.H., Zhang, C.Y., Wang, I.X., Shang, Q.H., Zhang, G.G. and Yang, W.R. (2018) Effect of dietary supplementation of Enterococcus faecium on growth, intestinal morphology, and selected microbial populations of piglets. Livest. Sci., 210(2): 111-117.

16. Hu, L., Che, L., Su, G., Xuan, Y., Luo, G., Han, F., Wu, Y., Tian, G., Wu, C., Fang, Z., Lin, Y., Xu, S. and Wu, D. (2014) Inclusion of yeast-derived protein in weanling diet improves growth performance, intestinal health, and antioxidant capability of piglets. Czech. J. Anim. Sci., 59(7): 327-336.

17. Halpern, B.P. (2000) Glutamate and the flavor of foods. $J$. Nutr., 130(4): 910-914.

18. Assoni, A.D., Amorim, A.B., Saleh, M.A.D., Tse, M.L.P. and Berto, D.A. (2017) Dietary glutamine, glutamic acid and nucleotide supplementation accelerate carbon turnover ( $1313 \mathrm{C})$ on stomach of weaned piglets. Anim. Nutr., 3(3): 225-231.

19. Santos, A.V., Fialho, E.T., Zangerộnimo, M.G., Cantarelli, V.S., Teofilo, T.S. and Molino, J.P. (2016) Additive antibiotic, probiotic and prebiotic for early weaned piglets. Ciencia Anim. Bras., 17(1): 1-10.

20. Wijtten, P.J.A., Meulen, J. and Verstegen, M.W.A. (2011) Intestinal barrier function and absorption in pigs after weaning: A review. Br. J. Nutr., 105(7): 967-981.

21. dos Anjos, C.M., Gois, F.D., dos Anjos, C.M., Rocha, A.S., Castro, D.E., Allaman, I.B., Silva, F.L., Carvalho, P.L.O., Meneghetti, C. and Costa, L.B. (2019) Effects of dietary beta-glucans, glucomannans and mannan oligosaccharides or chlorohydroxyquinoline on the performance, diarrhea, hematological parameters, organ weight and intestinal health of weanling pigs. Livest. Sci., 223(5): 39-46.

22. Wu, Y., Jiang, Z., Zheng, C., Wang, L., Zhu, C., Yang, X., Wen, X. and Ma, X. (2015) Effects of protein sources and levels in antibiotic-free diets on diarrhea, intestinal morphology, and expression of tight junctions in weaned piglets. Anim. Nutr., 1(3): 170-176.

23. Kohn, R.A., Dinneen, M.M. and Russek-Cohen, E. (2005) Using blood urea nitrogen to predict nitrogen excretion and efficiency of nitrogen utilization in cattle, sheep, goats, horses, pigs, and rats. J. Anim. Sci., 83(4): 879-889.

24. Oh, H.K., Choi, H.B., Ju, W.S., Chung, C.S. and Kim, Y.Y. (2010) Effects of space allocation on growth performance and immune system in weaning pigs. Livest. Sci., 132(1): 113-118.

25. Hedegaard, C.J., Strube, M.L., Hansen, M.B., Lindved, B.K., Lihme, A., Boye, M. and Heegaard, P.M.H. (2016) Natural pig plasma immunoglobulins have anti-bacterial effects: Potential for use as feed supplement for treatment of intestinal infections in pigs. PLoS One, 11(1): Article ID 0147373.

26. Wang, T., Fu, Y.M., Lv, J.L., Jiang, H.S., Li, Y.P., Chen, C.Y. and Zuo, C.M. (2003) Effects of mini-peptides on the growth performance and the development of small intestines in weaning piglets. Anim. Husbandry Vet. Med., 35(6): 4-8.

27. Volman, J.J., Ramakers, J.D. and Plat, J. (2008) Dietary modulation of immune function by $\beta$-glucans. Physiol. Behav., 94(2): 276-284.

28. Czech, A., Smolczyk, A., Ognik, K., Wlazlo, L., Nowakowicz-Debek, B. and Kiesz, M. (2018) Effect of dietary supplementation with Yarrowia lipolytica or Saccharomyces cerevisiae yeast and probiotic additives on haematological parameters and the gut microbiota in piglets. Res. Vet. Sci., 119(6): 221-227.

29. Yang, H., Magilnick, N., Lee, C., Kalmaz, D., Ou, X., Chan, J.Y. and Lu, S.C. (2005) Nrf1 and Nrf2 regulate rat glutamate-cysteine ligase catalytic subunit transcription indirectly via NF-KB and AP-1. Mol. Cell Biol., 25(14): 5933-5946.

30. Franco, R. and Cidlowski, J.A. (2009) Apoptosis and glutathione: Beyond an antioxidant. Cell. Death. Differ., 16(10): 1303-1314.

31. Salobir, J., Rezar, V., Pajk, T. and Levart, A. (2005) Effect of nucleotide supplementation on lymphocyte DNA damage induced by dietary oxidative stress in pigs. Anim. Sci., 81(1): 135-140.

32. Liu, G., Martínez, Y., Ren, W., Ni, H., Al-Dhabi, A.A., Duraipandiyan. V. and Yin, Y. (2017) Dietary Saccharomyces cerevisiae cell wall extract supplementation alleviates oxidative stress and modulates serum amino acids profiles in weaned piglets. Oxid. Med. Cell Longev., 2017(12): 3967493 
33. Sommer, F. and Bäckhed, F. (2013) The gut microbiota-masters of host development and physiology. Nat. Rev. Microbiol., 11(4): 227-238.

34. Park, J.H., Lee, S.I. and Kim, I.H. (2018) Effect of dietary $\beta$-glucan supplementation on growth performance, nutrient digestibility, and characteristics of feces in weaned pigs. $J$.
Appl. Anim. Res., 46(1): 1193-1197.

35. Zhou, T.X., Jung, J.H., Zhang, Z.F. and Kim, I.H. (2013) Effect of dietary $\beta$-glucan on growth performance, fecal microbial shedding and immunological responses after lipopolysaccharides challenge in weaned pigs. Anim. Feed Sci. Technol., 179(1): 85-92. 